\title{
The Magnitude of Adherence Diabetic Patients Toward Their Anti-diabetic Medication and Associated Factors in Asmara, Eritrea
}

\author{
Daniel Tikue Asrat ${ }^{*}$, Robiel Ankeste, Amanuel Tesfit, Naod Fsseha, Luwam Russom, \\ Ghirmay Yohannes, Frezghi Hidray, Hager Tesfaselassie
}

Department of Nursing and Public Health, Asmara College of Health Sciences, Asmara, Eritrea

Email address:

danitkku21@gmail.com (D. T. Asrat)

${ }^{*}$ Corresponding author

To cite this article:

Daniel Tikue Asrat, Robiel Ankeste, Amanuel Tesfit, Naod Fsseha, Luwam Russom, Ghirmay Yohannes, Frezghi Hidray, Hager Tesfaselassie. The Magnitude of Adherence Diabetic Patients Toward Their Anti-diabetic Medication and Associated Factors in Asmara, Eritrea. Journal of Drug Design and Medicinal Chemistry. Vol. 6, No. 4, 2020, pp. 39-46. doi: 10.11648/j.jddmc.20200604.11

Received: August 29, 2020; Accepted: September 16, 2020; Published: December 16, 2020

\begin{abstract}
Diabetes mellitus is a growing global health problem that affects individuals of all ages. Anti-diabetic medications are integral for glycemic control in diabetes. Lack of adherence to drugs can alter blood glucose levels and can lead to treatment failure, accelerated development of complications, and increased morbidity, mortality, and disability. In Eritrea, adherence to anti-diabetic medication is not well studied so far. The study aimed to assess the magnitude of adherence of diabetic patients toward their anti-diabetes medication and associated factors in the diabetic clinic of Halibut National Referral Hospital. A descriptive cross-sectional study was conducted in Asmara Halibet National Referral Hospital diabetic clinic from February 01 to May 31, 2019. Subjects of the study were all diabetic patients 16 years and above and had been on diabetic treatment for not less than six months. The sample size of this study was 205 determined using Crecy \& Morgan formula and convenience non-probability sampling was used to select study participants. Data were collected through an interview questionnaire assessed using self-report which then, cleaned, coded, and entered to excel and exported to SPSS for Windows version 20.0. Descriptive and inferential statistics were done to determine adherence to anti-diabetic medication and the associated factors. A total of 205 study participants were interviewed with a response rate of $100 \%$. The level of adherence was found to be $86.3 \%$. Factors found to be significantly associated with anti-diabetes medication were duration of diabetes (Pvalue $=0.001$ ), Health education about $\mathrm{DM}$ and its medications ( $\mathrm{P}$-value $=0.004)$, taking multiple medication ( $\mathrm{P}$-Value $=0.018$ ), forgetfulness ( $\mathrm{P}$-value $=0.000$ ), and monitoring of blood glucose level ( $\mathrm{p}$-value $=0.06$ ). In conclusion, the majority of respondents $86.3 \%$ in this study were found to be adherent to their anti-diabetic medications. Strategies that further improves anti-diabetic drug availability, provide health education, reduce the intervals of visits for follow-ups on diabetic care, and giving explicit information and persistent close family support for those taking multiple medications may help in improving adherence levels among patients with diabetes.
\end{abstract}

Keywords: Diabetes Mellitus, Adherence, Patients

\section{Background}

Diabetes mellitus is unquestionably one of the fastestgrowing public health problems worldwide. According to the International Diabetes Federation (IDF), 463 million people were living with diabetes, 4.2 million deaths due to diabetes caused and $79 \%$ of adults with diabetes were living in lowand middle-income countries, moreover diabetes caused at least USD 760 billion in health expenditure in $2019-10 \%$ of total spending on adults in 2019 , with an expected 700 million by 2045 [1].

According to t HIMS diabetes control program of Eritrea, diabetes mellitus is one of the leading causes of morbidity and mortality mainly in adults; a total of 98167 new cases and 1194 deaths of DM were reported from hospitals and health centers in the years $1998-2017$ [2]. Moreover, 695 
amputations due to DM were also reported between 20062012 indicating that it is not only the leading cause of morbidity but also a cause of disability. Diabetes mellitus was accountable for $0.4 \%$ of morbidity and $2.7 \%$ of the total reported deaths in 2012 [3].

One of the key measurements of healthcare quality in diabetes management is adherence to prescribed medications. According to WHO medication adherence or compliance is the extent to which an individual is taking their medication as instructed by a health care professional [4]. Drugs or medications constitute a vital component in the management of diabetes, but it is a fact that a lot of diabetic patients find it difficult to adhere to their drug regimens. The trouble of Non-adherence to prescribed medicinal treatment remains a challenge for medical professionals and the community; consequently, numerous patients did not get effective benefits from medical treatment. This leads to poor health outcomes, lower quality of life, and increased health care costs. Despite the improvement in adherence research, nonadherence rates have remained nearly unchanged in the last decades $[5,6]$.

Effectual management of diabetes is declining morbidity, mortality, and health care utilization, primarily decreasing the charges and burden to the government and society. People with diabetes who did not adhere to treatment have significantly worse clinical outcomes compared to patients who adhered to treatment [7] Even though a lot of emphases was made on patients regarding the significance of proper medication use, many patients poorly adhere to drugs mainly for chronic diseases and fall short of achievable health goals [8].

Non-adherence is association factors that are patientcentered, therapy-related, or healthcare system related [7, 9]. The patient-center factors can be demographic (age, gender, educational level, and marital status) and psychological (patients' beliefs and motivation towards the therapy, negative attitude, patient-prescriber relationship, understanding of health issues, and patients' knowledge [10, 11] The therapy-related factors include the route of administration, duration of treatment, the complexity of treatment, type of medication and the side effects of the medicines. The factors linked to the healthcare system include availability and accessibility of health care, and the health provider-patient interactions [12].

Non-adherence, poverty, lack of knowledge, and poor follow-ups are the main factors observed in poor glycemic control. Non-adherence to prescribed medication schedule has been and continues to be a major problem in the world. In chronic disease, it has been described as taking less than $80 \%$ of the prescribed treatment. Previous studies have found adherence to diabetes treatment generally to be sub-optimal ranging $(23 \%-77 \%)$ [13].

During our clinical posting time, we have witnessed many diabetic patients with severe complications and further admission to the hospital. So we came up with an idea that whether these complications were of patients' non-adherence to their anti-diabetic medication or any other possible factors?
There is a need for a continuous appraisal for patients with DM, as it is exhausting in taking the drug for continual time and paying a large amount of money, resulting in nonadherence among patients. This is observed mainly in lowincome developing countries; the major cause includes such as economic insecurity and inadequate access to health care facilities that led to an increase in the incidence of nonadherence to anti-diabetic medication. In resource-limited countries like Eritrea, the prevalence of economic instability, low literacy level, scanty evidence-based research that evaluates medication adherence and restricted access to health care facilities might have led to the increased incidence of medication non-adherence. Identification of the factors leading to non-adherence to a prescribed treatment can help in planning interventions to overcome these barriers.

The purpose of this study was to assess the adherence and associated factors in determining the magnitude at Halibut Regional Referral Hospital, Diabetic clinic from February to May. Therefore, this evidence-based research provides baseline information regarding the magnitude of adherence, since there is no study in Eritrea about adherence and to determine various non-adherence associated factors among patients that are using an antidiabetic medication. This information will help health planners at the $\mathrm{MOH}$ and specifically Halibet Regional Referral Hospital health management staff, for the continuity of medications and prevention of morbidity, disability, and deaths due to DM.

\section{Material and Method}

\subsection{Study Design and Area}

This was a cross-sectional study conducted at the diabetes clinic of Halibut National Referral Hospital from February 1 to May 30, 2019. This hospital is located in the Northeast part of Asmara, the capital city of Eritrea. It is a tertiary level hospital acting as a referral hospital and teaching center. Outpatient and inpatients care services are given on a daily except Sunday. Patients receive free medical care including medicines and laboratory investigations and attend the clinics at the scheduled time for continuous monitoring and consultation regarding their illness.

\subsection{Participant in the Study}

A total of 205 diabetic patients who were registered and have been taking anti-diabetes medication for more than six months were included in this study. Subjects were above the age of 16 years who were attending the diabetic clinics and gave informed consent to participate in the study.

\subsection{Sampling Method \& Sampling Size}

There were about 7000 registered clients in the diabetic clinic of Halibut National Referral Hospital who were taking the anti-diabetes medication regularly as an outpatient follow-up. The study sample size was found to be 190, 
adding up a $10 \%$ non-response rate the final sample size was 205. The samples were selected by convenience nonprobability sampling method.

\subsection{Data Collection}

The research team conducted the study by approaching patients on their regular visits to the diabetic clinic of Halibut National Referral Hospital. Data was collected using interview guided questionnaire. The questionnaire included socio-demographic data, medication adherence level, and diabetic profile, and factors related to non-adherence. Questions were adopted, modified, and translated into the local language (Tigrigna). Data were cleaned and checked at the end of each interview for completeness, before data entry to excel.

The tool of a scoring system for the adherence level was based on self-reports of how patients had been taking medication one week before the interview period. The number of times doses were missed was calculated based on the patients' medication regimen which was obtained from their interview. Patients, who scored $0-79 \%$ of the prescribed dose from the last seven days, were poorly adhered and those who scored $80-100 \%$ were good adhered [14].

\subsection{Data Analysis Methods}

The study used quantitative data according to the variables that the research questions need to answer. Data were entered using excel and exported to Statistical Package for Social Sciences (SPSS) for Windows version 20.0 for cleaning and analysis. The Chi-square analysis method was used to find out the strength of the associations of each independent variable with the dependent variables in which crude odds ratio with their corresponding $95 \%$ confidence intervals were used to describe these associations. A p-value of less than 0.05 was considered statistically significant.

\subsection{Ethical Consideration}

The ethical issue was dealt with first by obtaining a permission letter from the School of Nursing, ACHS, and then taken to the Halibut medical officer. The participants were adequately informed about the purpose, method, and expected outcome of the study by the researchers. Verbal consent was obtained and secrecy was maintained highly confidential. The responders' right to refuse or withdraw from the study was also respected fully. And all patients who were willing to participate in the study were kindly requested to put their signatures.

\section{Result}

Table 1. Distribution socio-demographic characteristic.

\begin{tabular}{llll}
\hline Variables & & Frequency & Percentage (\%) \\
\hline \multirow{4}{*}{ Age } & $16-45$ & 40 & 19.5 \\
& $46-60$ & 81 & 39.5 \\
& $61-75$ & 71 & 34.6 \\
\hline
\end{tabular}

\begin{tabular}{|c|c|c|c|}
\hline Variables & & Frequency & Percentage (\%) \\
\hline \multirow{2}{*}{ Sex } & Male & 108 & 52.7 \\
\hline & Female & 97 & 47.3 \\
\hline \multirow{2}{*}{ address } & Urban & 181 & 88.3 \\
\hline & Rural & 24 & 11.7 \\
\hline \multirow{2}{*}{ religion } & Christian & 87 & 91.2 \\
\hline & Muslim & 18 & 8.8 \\
\hline \multirow{5}{*}{ Educational } & Illiterate & 8 & 3.9 \\
\hline & Primary & 19 & 9.3 \\
\hline & Junior & 55 & 26.8 \\
\hline & Secondary & 76 & 37.1 \\
\hline & Collage and above & 47 & 22.9 \\
\hline \multirow{5}{*}{ Marital status } & Single & 23 & 11.2 \\
\hline & Married & 148 & 72.2 \\
\hline & Widowed & 20 & 9.8 \\
\hline & Divorce & 9 & 4.4 \\
\hline & Separate & 5 & 2.4 \\
\hline \multirow{7}{*}{ Occupation } & Farmer & 5 & 2.4 \\
\hline & Housewife & 45 & 22 \\
\hline & Civil employ & 53 & 25.9 \\
\hline & Military employ & 23 & 11.2 \\
\hline & Trader & 12 & 5.9 \\
\hline & Student & 61 & 29.8 \\
\hline & Unemployed & 6 & 2.9 \\
\hline
\end{tabular}

A total of 205 respondents were interviewed with a $100 \%$ response rate. The age of respondents ranged from 20-88 years with SD 14 years. More than half $(52.7 \%)$ of the respondents were Males. The majority of the respondents were from urban areas $181(88.3 \%)$ and Christian religion 187 (91.2\%). Almost (37.1\%) had an educational background secondary school followed by college levels (22.9\%) education. Around three fourth (72.2\%) of the respondents reported that they were married. (29.9\%) were students followed by a civil employee $(25.9 \%)$.

Table 2. Distribution of medication and clinical characteristics of the study participants.

\begin{tabular}{llll}
\hline Variables & & Frequency & Percentage \\
\hline Type of DM & T1D & 47 & 22.9 \\
& T2D & 158 & 77.1 \\
Age of onset & <30 year old & 28 & 13.7 \\
of DM & $\geq 30$ year old & 177 & 86.3 \\
Duration of & <5 years & 52 & 25.4 \\
DM & $\geq 5$ years & 153 & 74.6 \\
Family & Yes & 63 & 30.7 \\
history & No & 142 & 69.3 \\
Type of DM & Oral only & 101 & 49.3 \\
drugs & Injection only & 103 & 50.2 \\
& Both oral and injection & 1 & 0.5 \\
Co-morbid & yes & 85 & 41.5 \\
disease & No & 120 & 58.5 \\
& hypertension & 65 & 76.4 \\
Comorbid & Kidney disease & 6 & 7.1 \\
disease & Respiratory disease & 2 & 2.4 \\
& Others, HIV, liver disease & 12 & 14.1 \\
\hline
\end{tabular}

More than three fourth $(77.1 \%)$ of the subjects were known as T2DM. Regarding the age of onset of DM, the majority of the respondents $(83.3 \%)$ were $\geq 30$ years old when first diagnosed with DM. Most of the respondents (74.6\%) had a duration of five years and above with the 
disease. The majority of the respondents $(69.3 \%)$ reported that they had no family history of diabetes. An almost equal number of patients, $51.2 \%$ and $49.3 \%$ told that they take an injection and oral only respectively. Out of all the respondents, $41.5 \%$ had comorbidity. Details of the respondents are summarized in Table 2.
Table 3. Distribution of adherence to anti-diabetic medication $(N=205)$.

\begin{tabular}{lll}
\hline Adherence level & Frequency & Percentage \\
\hline Good adherence & 177 & $86.3 \%$ \\
Poor adherence & 28 & $13.7 \%$ \\
\hline
\end{tabular}

Out of 205 participants, $86.3 \%$ had good adherence whereas the remaining $13.7 \%$ had poor adherence

Table 4. Associations of selected socio-demographic, clinical, and medication characteristics with adherence anti-diabetic medication.

\begin{tabular}{|c|c|c|c|c|c|c|}
\hline \multirow{3}{*}{ Variables } & & \multicolumn{4}{|c|}{ Level of adherence } & \multirow{3}{*}{ p-value } \\
\hline & & \multicolumn{2}{|l|}{ Adhered } & \multicolumn{2}{|c|}{ Non adhered } & \\
\hline & & frequency & Percent age & Percentage & Frequency & \\
\hline \multirow{2}{*}{ Sex } & Male & 94 & 87 & 14 & 13 & \multirow{2}{*}{0.760} \\
\hline & Female & 83 & 85.6 & 14 & 14.4 & \\
\hline \multirow{4}{*}{ Age } & $20-45$ & 35 & 87.5 & 5 & 12.5 & \multirow{4}{*}{0.851} \\
\hline & $46-60$ & 67 & 82.7 & 14 & 17.3 & \\
\hline & $61-75$ & 65 & 91.5 & 6 & 8.5 & \\
\hline & 76 and above & 10 & 76.9 & 3 & 23.1 & \\
\hline \multirow{2}{*}{ Address } & Asmara & 156 & 86.2 & 25 & 13.8 & \multirow{2}{*}{.860} \\
\hline & Outside Asmara & 21 & 87.5 & 3 & 12.5 & \\
\hline \multirow{2}{*}{ Religion } & Christian & 159 & 85 & 28 & 15 & \multirow{2}{*}{.077} \\
\hline & Muslim & 18 & 100 & 0 & 0 & \\
\hline \multirow{5}{*}{ Education } & Illiterate & 5 & 62.5 & 3 & 37.5 & \multirow{5}{*}{.186} \\
\hline & Primary & 15 & 78.9 & 4 & 21.1 & \\
\hline & Junior & 49 & 89.1 & 6 & 10.95 & \\
\hline & Secondary & 65 & 85.5 & 11 & 14.5 & \\
\hline & Collage and above & 43 & 91.5 & 4 & 8.5 & \\
\hline \multirow{5}{*}{ Marital status } & Single & 28 & 91.3 & 2 & 8.7 & \multirow{5}{*}{.740} \\
\hline & Married & 129 & 87.2 & 19 & 12.8 & \\
\hline & Widowed & 16 & 80 & 4 & 20 & \\
\hline & Divorced & 7 & 77.8 & 2 & 22.2 & \\
\hline & Separated & 4 & 80 & 1 & 20 & \\
\hline \multirow{7}{*}{ Occupation } & Farmer & 4 & 80 & 1 & 20 & \multirow{7}{*}{.312} \\
\hline & House wife & 34 & 75.6 & 11 & 24.4 & \\
\hline & Civil employee & 46 & 86.8 & 7 & 13.2 & \\
\hline & Military employee & 21 & 91.3 & 2 & 8.7 & \\
\hline & Merchant & 11 & 91.7 & 1 & 8.3 & \\
\hline & Student & 55 & 90.2 & 6 & 9.8 & \\
\hline & Unemployed & 6 & 100 & 0 & 0 & \\
\hline \multirow{2}{*}{ Type of DM } & $\mathrm{T} 1 \mathrm{D}$ & 42 & 89.4 & 5 & 10.6 & \multirow{2}{*}{.492} \\
\hline & $\mathrm{T} 2 \mathrm{D}$ & 135 & 85.4 & 23 & 14.6 & \\
\hline \multirow{3}{*}{ DM drug } & Oral only & 88 & 87.1 & 13 & 12.9 & \multirow{3}{*}{.868} \\
\hline & Injection only & 88 & 85.4 & 15 & 14.6 & \\
\hline & Both oral and injection & 1 & 100 & 0 & 0 & \\
\hline \multirow{2}{*}{ Comorbid disease } & Yes & 68 & 80 & 17 & 20 & \multirow{2}{*}{.026} \\
\hline & No & 109 & 90.8 & 11 & 9.2 & \\
\hline \multirow{2}{*}{ Duration of $\mathrm{dm}$} & $<5 \mathrm{yrs}$ & & 73.1 & & 26.90 & \\
\hline & $>5 \mathrm{yrs}$ & & 90.8 & & 9.20 & 0.001 \\
\hline
\end{tabular}

Numerous factors, comprising socio-demographic characteristic (age, sex, address, religion, ethnicity, educational level, marital status, occupation, monthly income) and medication and clinical characteristics (a type of DM, type of DM drugs and frequency taken per day, family history, comorbid disease, duration of DM and age of disease onset) were analyzed to determine any association with adherence to anti-diabetic medications. The only duration of DM and co-morbid diseases had a statistically significant association with adherence to the ant-diabetic medication at $P$-Value 0.001 and 0.026 respectively. Details are summarized in
Table 4.

At crude odds ratio analysis, factors associated with medication adherence were: monitor blood glucose level regularly $(\mathrm{OR}=2.078,95 \% \mathrm{CI}=0.604-7.142)$, having ever attending health education $(\mathrm{OR}=1.621,95 \% \mathrm{CI}=0.179$ $14.639)$, availability of anti-diabetic medication $(\mathrm{OR}=76.174$, $95 \% \mathrm{CI}=17.520$ - 331.184), forgetfulness ( $\mathrm{OR}=0.14195 \%$ $\mathrm{CI}=0.037-0.531)$, taking Multiple medications $(\mathrm{OR}=0.550$ $95 \% \mathrm{CI}=0.164-1.841)$ and Financial problem $(\mathrm{OR}=0.883$, $95 \% \mathrm{CI}=0.221-3.533)$. Details are summarized in Table 5 below. 
Table 5. Association between factors and the level of adherence.

\begin{tabular}{|c|c|c|c|c|c|c|c|}
\hline \multirow{3}{*}{ Variables } & & \multicolumn{4}{|c|}{ Adherence level } & \multirow{3}{*}{ Odds Ratio } & \multirow{3}{*}{ P-value } \\
\hline & & \multicolumn{2}{|c|}{ Adherence } & \multicolumn{2}{|c|}{ Non-adherence } & & \\
\hline & & Frequency & Percentage & Frequency & Percentage & & \\
\hline \multirow{2}{*}{ Monitor blood glucose regularly } & Yes & 99 & 90.8 & 10 & 9.2 & \multirow{2}{*}{$2.078(0.604-7.142)$} & \multirow{2}{*}{0.046} \\
\hline & No & 78 & 81.2 & 18 & 18.8 & & \\
\hline \multirow{2}{*}{ Attending health education } & Yes & 170 & 88.1 & 23 & 11.9 & \multirow{2}{*}{$1.621(0.179-14.639)$} & \multirow{2}{*}{0.004} \\
\hline & No & 7 & 58.3 & 5 & 41.7 & & \\
\hline \multirow{2}{*}{ Availability of medication } & Yes & 172 & 94.5 & 10 & 5.5 & \multirow{2}{*}{$76.174(17.520$ - 331.184) } & \multirow{2}{*}{0.000} \\
\hline & No & 5 & 21.7 & 18 & 78.3 & & \\
\hline \multirow{2}{*}{$\begin{array}{l}\text { Modification of dosing and } \\
\text { timing of drug }\end{array}$} & Yes & 34 & 87.2 & 5 & 12.7 & \multirow{2}{*}{$3.076(0.546-17.324)$} & \multirow{2}{*}{0.866} \\
\hline & No & 143 & 86.1 & 23 & 13.9 & & \\
\hline \multirow{2}{*}{ Forgetfulness } & Yes & 29 & 65.9 & 15 & 34.1 & \multirow{2}{*}{$0.141(0.037-0.531)$} & \multirow{2}{*}{0.000} \\
\hline & No & 148 & 91.9 & 13 & 8.1 & & \\
\hline \multirow{2}{*}{ Multiple medications } & Yes & 60 & 78.9 & 16 & 21.1 & \multirow{2}{*}{$0.550(0.164-1.841)$} & \multirow{2}{*}{0.018} \\
\hline & No & 117 & 90.7 & 12 & 9.3 & & \\
\hline \multirow{2}{*}{ Complexity drug regimen } & Yes & 121 & 85.8 & 20 & 14.2 & \multirow{2}{*}{$2.137(0.602-7.587)$} & \multirow{2}{*}{0.776} \\
\hline & No & 55 & 87.3 & 8 & 12.7 & & \\
\hline \multirow{2}{*}{ Financial problem } & Yes & 41 & 82 & 9 & $18 \%$ & \multirow{2}{*}{$0.883(0.221-3.533)$} & \multirow{2}{*}{0.340} \\
\hline & No & 136 & 87.7 & 19 & 12.3 & & \\
\hline \multirow{2}{*}{ Habit of alcohol } & Yes & 11 & 78.6 & 14 & 21.3 & \multirow{2}{*}{$0.761(0.086-6.741)$} & \multirow{2}{*}{0.380} \\
\hline & No & 166 & 86.9 & 25 & 13.1 & & \\
\hline & Yes & 3 & 75 & 1 & 25 & $5766(0.018-1811251)$ & 0.540 \\
\hline Believes the medication useless & No & 174 & 86.6 & 27 & 13.4 & $5 . / 66(0.018-1811.251)$ & 0.540 \\
\hline Feeling the given dose is high & Yes & 27 & 79.4 & 7 & 20.3 & $0390(0.089-1712)$ & 0180 \\
\hline r & No & 150 & 87.7 & 21 & 12.3 & $0.090(0.009-1.112)$ & 0.100 \\
\hline
\end{tabular}

\section{Discussion}

This study revealed that the adherence rate of the respondents to their medication was $86.3 \%$ with almost similar rates in both males and females which are $87 \%$ and $85.6 \%$ respectively. About five in every six respondents adhered in a satisfactory way to their diabetic medication based on self-reports at an adherence index of $80 \%$. Similar adherence rates had been reported previously from studies conducted in UAE in which male's adherence was $84 \%$ and females' adherence was $87 \%$ [15], Uganda (83.3\%)(14) and Gondar Ethiopia (85.1\%)(16). However, it is higher than the medication adherence rate reported in Botswana (58.2\%) (17), Tanzania (71.2\%) (18), New York (75\%) (19), Ghana (68.5\%) (20), Nigeria (72.5) (21) and Adama Ethiopia (72.2\%) (22). The disparity in adherence levels may be attributed to differences in metrics to assess adherence, and/or differences in health care settings, time gape of study, financial cost, and socioeconomic status. Concerning this study patients receive free antidiabetic drugs while in low-income countries patients were might pay for drugs and clinic consultations. Therefore associated financial costs may discourage or becomes late patients from re-filling prescribed medication and this becomes hinder their adherence and the high costs of the prescribed medications.

Higher adherence rates were shown among patients with an educational level of junior (89.1\%), secondary (85.5\%), collage and above $(91.5 \%)$ and were found to be the most compliant to the prescribed treatment whereas lower adherence rates were found among illiterates $(62.5 \%)$ and primary $(78.9 \%)$ level of education. Despite the difference in rates of adherence with educational levels, there is no statistically significant association $(\mathrm{P}$-value $=0.186)$. A similar study conducted in the UAE reported higher adherence rates among patients with graduate-level (bachelor's degree) (85.8\%) and post-graduate degree (master's degree) (84.6\%) [15]. Another study conducted in Adama Ethiopia revealed higher adherence rates among graduate patients (diploma) $(80.7 \%)$ and secondary school (80\%) [25]. this finding could be explained as the educational level of an individual's increase their knowledge could also be lifted which leads to better understanding. In the case of diabetes, those who have a higher educational level could easily grasp the information provided to them.

In this study, $20 \%$ of those who had the co-morbid disease have not adhered to the prescribed drug therapy and this is statistically significant at a p-value of (0.026). Likewise, the same results were noted in Adama Ethiopia 25\% [22] and Zimbabwe $23 \%$ [23]. As a result of taking multiple medications patient could be confused with the drug regimen and may feel bored to take multiple drugs. This implies that having a co-morbid disease additionally could have affected the rate of adherence to the prescribed drugs.

Another significant association found in this study was the duration of diabetes with the adherence status of the participants at $\mathrm{p}$-value $(0.001)$. Patients with five years and above since medically diagnosed as having diabetes were observed to be more likely adherent than those with less than five years of duration with an adherence level of $90.8 \%$ and $73 \%$ respectively. This outcome is similar to the results of the study done in Gonder Ethiopia in which patients with five years and above a duration of diabetes had an adherence level of $85.0 \%$ and patients with diabetes duration of fewer than five years had $78.0 \%$ adherence level [16]. Another study from Uganda reported an adherence level of $88.6 \%$ and $77.6 \%$ among patients with five and above years of diabetic duration as 
compared to patients with less than five years of diabetes duration respectively [14]. This could be related to the experience of the patients and their bond with the health workers or caregivers. The longer the time a patient follows a treatment the better could be the understanding about the regularity, schedules, and perceived benefits. Besides, with the length of time, patient and care provider relations could be strengthened leading to close communication and encouraging care providers to convey every piece of information and advice. Meanwhile motivating patients to follow the given instruction and advice with trust ship and altogether improving adherence.

According to the respondents of this study, the common reasons for non-adherence to anti-diabetes medications were modifiable factors such as forgetfulness and non-monitoring blood glucose level. Forgetfulness accounts for $34.1 \%$ and was statistically significant $\quad(\mathrm{OR}=0.141 \quad 95 \% \quad \mathrm{CI}=0.037$ $0.531)$. This finding was in line with a study from Ghana and Adama Ethiopia where 45.5\% [20] and 53.9\% [22] subjects reported forgetfulness respectively. In contrast, a study from Tanzania stated financial factors as the main reason for nonadherence to anti-diabetic medications with a value of $35.1 \%$ [18].

The financial factor could not be such an influencer in Eritrea as patients receive free medical care including medicines and laboratory investigations. Forget fullness as a barrier could be solved by supporting patients in organizing their medications with dosing alarms or specific remainder techniques. Moreover, a family member or close friend support could have a role in avoiding forgetfulness. Regular monitoring of blood glucose levels was found to be significantly associated with anti-diabetes medication adherence $(\mathrm{OR}=2.078,95 \% \mathrm{CI}=0.604-7.142)$. More than half of the respondents $(53.2 \%)$ in this study reported that they monitor their blood glucose levels regularly and from those $90.8 \%$ were adhering to their medication. Similarly, a study conducted in the UAE found that more than $95 \%$ of the respondents were monitoring their blood glucose levels regularly [15]. While a study from Nigeria had the opposite results in which the majority of the participants $(80 \%)$ did not monitor their blood glucose levels regularly [21]. The practice of self-monitoring of blood glucose levels by patients could be a signal of their commitment to managing diabetes and could be rooted behind the reasons for the good adherence rate.

This study also found a significant association between health education about diabetes mellitus and the adherence level of patients with $88.1 \%$ of those patients who attended the health education sessions were adherent to their antidiabetes mediation $(\mathrm{OR}=1.621,95 \% \mathrm{CI}=0.179$ - 14.639). This finding is similar to studies done in Gondar Ethiopia (86\%) [16] and Uganda (84\%) [14]Where patients attending health education had a higher adherence rate and were significantly associated. Providing health education to patients about diabetes mellitus, its diagnosis, management, and other self-care advice related to diabetes could be effective in improving recruitment of patients into treatment programs, improving patients' health condition, and improving drug adherence. Education on diabetes selfmanagement can improve diabetes care. Having a 20 minutes discussion with a diabetes educator every three months before an office visit may help to achieve many goals. Therefore, it is very important to staff the diabetic clinics with adequate numbers of well-trained health workers who are willing to spend reasonable time with patients and provide up to date diabetic management guidelines [24].

Another significant association observed in this study was the association between the availability of anti-diabetes medication and adherence level to the medication $(\mathrm{OR}=76.174,95 \% \mathrm{CI}=17.520$ - 331.184). Almost all (94.5\%) of those who reported the availability of the drug is continuous (always) were adherent to their medications. A study conducted in Uganda indicated that 33.8\% [14] of the respondents had missed getting at least one of the drugs in their regimen. If drugs stock out-patients will go without drugs till the next scheduled visit or are forced to purchase their medications from private providers. Failure to afford medications could be a potential factor for poor adherence.

\section{Conclusion}

In this study, the overall adherence rate to anti-diabetes medication was high (86.3\%). Duration of diabetes mellitus, co-morbidity, forgetfulness, regular blood glucose level monitoring, attending health education about DM and its medication, and availability of the medication, were significantly associated with anti-diabetes medication adherence. Sex, age, religion, educational level, monthly income, marital status, types of DM, DM drugs, and frequency of dosage were not significantly associated with anti-diabetes medication adherence. The common reasons for non-adherence to anti-diabetes medication were forgetfulness and non-monitoring of blood glucose level regularly. Therefore, strategies that further improves anti-diabetic drug availability, provide health education, reduce the intervals of visits for follow-ups on diabetic care, and giving explicit information and persistent close family support for those taking multiple medications may help in improving adherence levels among patients with diabetes.

\section{Recommendation}

Detailed and comprehensive health education should be further increased to be given to the patients as well as family members about the disease and anti-diabetic medication. The hospitals should develop manual guidelines for patient education regarding adherence to medication and improving non-adherence factors. The barrier of forgetfulness can be overcome by assisting patients in organizing their medications with pillboxes and dosing alarms and family members can assist in medication adherence in those taking multiple medications. 


\section{Limitations of the Study}

Self-reported was used as the only method of measuring adherence. This method has the disadvantage of recall bias and eliciting an only socially acceptable response and hence, may overestimate the level of adherence moreover only registered patients who come for follow up care have participated in the study so this study cannot represent diabetic patients who were not registered. Due to the nature of the study design, the cause and effect relationship between an outcome variable and associated variable cannot be established.

\section{Abbreviations}

ACHS: Asmara College of Health Sciences; MOH: Ministry of Health; WHO: World Health Organization, SPSS: Statistical Package Social Science, DM: Diabetic Mellitus T1D: Type One Diabetic, IDF: International Diabetes Federation), T2D: Type Two Diabetic

\section{Funding}

There was no source of funding for the study, for the authors, or manuscript preparation.

\section{Conflict of Interest}

The authors declare that they have no competing interests.

\section{Authors' Contributions}

All authors participated in all phases of the study including topic selection, design, data collection, data analysis, interpretation, and presentation. Daniel contributes to writing this manuscript.

\section{Availability of Data and Materials}

The complete data set supporting the conclusions of this article is available from the corresponding author and can be accessed upon reasonable request.

\section{Acknowledgements}

We particularly want to express our deep gratitude and appreciation for the staff member of Halibut hospital of the diabetic unit for their cooperation during data collection. We are thankful to the clients of Halibet Hospital Diabetic Clinic, for agreeing to participate in this study as, without them, this study would not have been conceptualized.

\section{References}

[1] International Diabetes Federation. Diabetes Atlas: International Diabetes Federation 2019.
[2] Ministry of Health (2017). Diabetes Control Program: Annual report. Asmara, Eritrea.

[3] MOH (2012). National Steps Survey for Chronic Non Communicable Diseases and their Risk Factors, In DPC/NCD. Asmara, Eritrea.

[4] World Health Organization (2003). Adherence to long-term therapies, Evidence for action. Geneva, Switzerland.

[5] Cramer JA. (2004). A systematic review of adherence with medications for diabetes. Diabetes Care. Vol, 27, no. 5. pp 1218-1224, 2004

[6] R. M Jamous, W. M Sweileh, A. S Abu Taha, A. F Sawalha, S. H Zyoud and D. E (2011). Morisky adherence and satisfaction with oral hypoglycaemic medication pilot study in Palestine. International Journal of Clinical Pharmacy, vol 33 no. 6 pp 942-948, 2011.

[7] Pollack MF, Purayidathil FW, Bolge SC, Williams SA. (2010). Patient-reported tolerability issues with oral anti diabetic agents: Associations with adherence; treatment satisfaction and health-related quality of life. Diabetes Res Clin Pract. 2010; 87 (2): 204-10.

[8] Lee WC, Balu S, Cobden D, Joshi AV, Pashos CL (2006). Medication adherence and the associated health-economic impact among patients with type 2 diabetes mellitus converting to insulin pen therapy: An analysis of third-party managed care claims data. ClinTher. 2006; 28 (10): 1712-25.

[9] VanBruggen R, Gorter K, Stolk RP, Zuithoff P, Klungel OH, Rutten GE (2009). Refill adherence and polypharmacy among patients with type 2 diabetes in general practice. Pharmacoepidemiol Drug Saf. 2009; 18 (11): 983-91.

[10] Jin J, Sklar GE, Min Sen OV, Chuen Li S. (2008). Factors affecting therapeutic compliance: A review from the patients' perspective. TherClin Risk Manag. 2008; 4 (1): 269-86.

[11] Wong MCS, Kong APS, So W-Y, Jiang JY, Chan JCN, Griffiths SM. (2011). Adherence to Oral Hypoglycemic Agents in 26782 Chinese Patients: A Cohort Study. J ClinPharmacol. 2011; 51 (10): 1474-82.

[12] Hutchins V, Zhang B, Fleurence RL, Krishnarajah G, Graham $J$ (2011). A systematic review of adherence, treatment satisfaction and costs, in fixed-dose combination regimens in type 2 diabetes. Curr Med Res Opin. 2011; 27 (6): 1157-68.

[13] Kalyango JN, Owino E, Nambuya AP (2008) Non-adherence to diabetes treatment at Mulago Hospital in Uganda: prevalence and associated factors. Afr Health Sci 8: 67-73.

[14] James Bagonza, Elizeus Rutebemberwa and William Bazeyo (2015). Adherence to anti diabetic medication among patients with diabetes in eastern Uganda; a cross sectional study BMC Health Services Research 2015 15: 168. DOI: 10.1186/s12913-015-0820-5.

[15] Mohammed ARIFULLA, LishaJenny JOHN, Jayadevan SREEDHARAN, Jayakumary MUTTAPPALLYMYALIL, and Sheikh Altaf BASHA (2011). Patients' adherence to antidiabetic medications in a Hospital at Ajman, UAE, 2011.

[16] Mastewal Abebaw, Anteneh Messele, Mignote Hailu, and Fisseha Zewdu (2013). Adherence and associated factors towards antidibetic medication among type II diabetic patients on follow up at University of Gondar Hospital, Northwest Ethiopia. 
[17] Godfrey Mutashambara Rwegerera, Thato Moshomo, Marea Gaenamong, Taibat Aderonke Oyewo, Sivasomnath Gollakota, Francis Apolinary Mhimbira, Joseph Fadare, Brian Godman, Johanna C. Meyer, Yordanka Piña Rivera (2015). Antidiabetic medication adherence and associated factors among patients in Bostwana; implications for the future.

[18] Godfrey Mutashambara Rwegerera (2014. Adherence to antidiabetic drugs among patients with type 2 diabetes mellitus at Muhimbili National Hospital, Dar es Salaam, Tanzania. Pan African Medical Journal. 2014; 17: 252. Doi: 10.11604/pamj.2014.17.252.2972.

[19] MARLON RUSSELL KOENIGSBERG, DONALD BARTLETT and J. STEVEN CRAMER (2004). Facilitating treatment adherence with lifestyle changes in diabetes University at Buffalo, State University of New York School of Medicine and Biomedical Sciences, Buffalo, New York, 2004.

[20] Awuni Prosper Mandela Amaltinga (2017). Non adherence to diabetic medication among diabetic patients, a case study of Dormaa Hospital Ghana. Science Journal of Public Health. Vol. 5, No. 2, 2017, pp. 88-97. doi: 10.11648/j.sjph.20170502.15.
[21] Adisa R, Fakeye T and Fasanmade. (2011). A patients with Type 2 diabetes in a Tertiary Healthcare Setting In Southwestern Nigeria. Pharmacy Practice, 2011.

[22] Gelaw BK, Mohammed A, Tegegne GT, Defersha AD, Fromsa M, et al. (2014). Non Adherence and Contributing Factors among Ambulatory Patients with Anti Diabetic Medications in Adama Referral Hospital. Adv Pharmacoepidemiol Drug Saf 3: 169. doi: 10.4172/2167-1052.1000169.

[23] Winnie Mandewo, Edward, E Dodge, AuxiliaChidemeMunodawafa and George Mandewo. (2014) Non-adherence to treatment among diabetic patients attending outpatients clinic at Mutare Provincial Hospital, Manicaland Province, Zimbabwe. International Journal of Scientific \& Technology Research volume 3, issue 9, September 2014.

[24] American Diabetes Association (2009). Standards of Medical Care in Diabetes. Diabetes Care. 2009; 32 (Supplement 1): S13-61. 